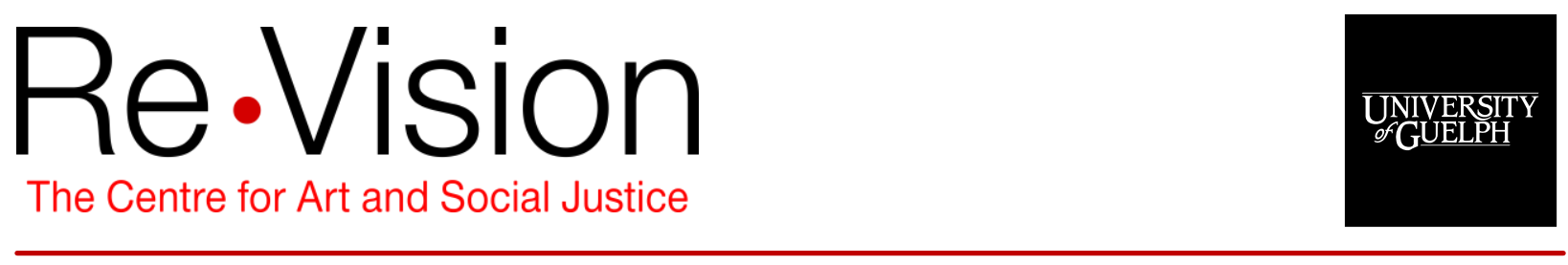

\title{
Fatness and Failing Citizenship
}

\author{
Jen Rinaldi \\ University of Ontario Institute of Technology \\ Carla Rice \\ University of Guelph \\ Andrea LaMarre \\ University of Guelph \\ Deborah McPhail \\ University of Manitoba \\ Elisabeth Harrison \\ York University
}

The article has been accepted for publication by Edinburgh University Press in Somatechnics: https://doi.org/10.3366/soma.2017.0219

\section{Recommended citation:}

Rinaldi, J., Rice, C., LaMarre, A., McPhail, D., \& Harrison, E. (2017). Fatness and failing citizenship. Somatechnics, 7(2), 218-233. https://doi.org/10.3366/soma.2017.0219 


\section{Fatness and Failing Citizenship}

Jen Rinaldi, Carla Rice, Andrea LaMarre, Deborah McPhail and Elisabeth Harrison

\section{Abstract:}

This article examines how queer persons negotiate the technologies of health deployed to shape sexual citizenship, especially in relation to body size. Beginning with the claim that fatness is always already queered, the authors bring Jasbir Puar's concept of homonationalism into conversation with Samantha Murray's argument that fat persons are positioned as failed citizens. The authors illustrate how fat embodied subjects confront problematics of belonging through analysing in-depth interviews conducted for a research project that investigated how members of queer communities come up against, are affected by and resist body image ideals and body management expectations. Interview excerpts are organised around sites of constraint, contestation and creativity: medical space, queer space and the body as space.

Keywords: Homonationalism, failed citizenship, fatness, queer theory, health.

Our collaborative, community-based research project, Through Thick \& Thin: Investigating Body Image \& Body Management Among Queer 
Women,,- engages with the question of how members of queer communities who identify as women? negotiate, are affected by and resist body image ideals and body management expectations. The research team consisted of queer and trans women and allies of varied races and ethnicities, class backgrounds, sizes and abilities. We came together to speak back to health research and practice that problematize nonnormative bodies and overlook the impacts of assumptions about body shape, size and satisfaction on diverse queer subjectivities. Our mixed methods approach included in-depth semi-structured interviews with 24 participants, who themselves occupied varied and compounding marginalised positions and had complex relationships with queerness and fatness.

Through Thick \& Thin participants were recruited using purposive sampling methods to ensure our sample population was diverse and reflected the complex makeup of queer communities. Given the fluidity of bodies, fatness is difficult to classify numerically but almost all participants did discuss experiences of being regarded as obese, overweight, too large

\footnotetext{
1 This project was funded by Women's College Hospital's Women's Xchange \$15K Challenge large-scale grant program. Our research team represents community partners Rainbow Health Ontario and Project ReVision as well as the following institutions: the University of Ontario Institute of Technology, the University of Guelph, Ryerson University, Trent University, the University of Manitoba, York University, and the Centre for Addiction and Mental Health.

2 Our research team used the term 'woman' through the duration of grant work to align with terminology used by our grant funder. However, our use of the term was left open and flexible so as to include a diverse range of gender identities and expressions, including persons who identified as trans, genderqueer, non-binary and butch.
} 
and fat. Interviews were transcribed and coded using a constructivist grounded theory methodology that recognised the interpretive role of researchers and the active role of participants as partners who 'act back on researchers' (Giddens 1984: 18).Coding and thematic analysis were undertaken to enable repeated engagement with thick descriptions and narratives of experiences in order to identify and organise these pieces into meaningful patterns.

In this article, we analyse the resulting research data to explore how queer persons negotiate technologies of health that police the boundaries of sexual citizenship especially in relation to size. Adopting a queer Deleuzian approach (Nigianni and Storr 2009), we take citizenship to mean recognition as a member of a political assemblage, whether that assemblage is imagined or materialises as a nation-state, local government, political movement or another politicised collectivity. We consider how size comes to matter in constructions of Canadian nationalism, and by extension Canadian homonationalism, and, how queer(ly) fat subjects are constructing, negotiating and resisting sexual citizenship with the technologies available to them and the territories they navigate.

Our findings are organised around four conceptual clusters. First, we consider how participants confront their relationship with biopolitical forces in the clinical encounter, including compulsory thinness which, like compulsory heterosexuality, polices and produces a biocitizenry, and works to responsibilise those failing to enact self-management scripts through weight loss. Next, we explore participants' relationship with their bodies - a relationship that neither stabilises solidly nor flows freely but is instead 
viscous in character, like the katamari moving through the world, adhering to and absorbing affects, $\frac{3}{-}$ meaning the ways queer women of our study experience themselves are complicated and contingent, bound up in affective experience and not always kind. Our next set of findings concerns participants' relationship to homonationalist queer culture and community, where homonationalism refers to the conceptualisation of successful and failed forms of sexual citizenship. We end on participants taking active, deliberate roles in the construction and presentation of their bodily becomings and in so doing reorganising the possibilities for their communities and worlds.

\section{The Threat of Fat: Situating Fat Bodies in a Canadian Policy}

\section{Context}

We expand homonationalism - the processes by which acceptable and adverse forms of sexual citizenship are produced (Puar 2007) - to encompass how the techne's - as appropriate practices - of medicine and public policy pertaining to size are taken up and/or contested by queer subjects in the various spaces they occupy so as to sediment or destabilise the boundaries of sexual citizenship. Despite a growing body of academic literature and federal and provincial policies that seek to end an 'obesity epidemic' that is constructed as both a public health threat and an expense

\footnotetext{
${ }^{3}$ We are borrowing a term from the video game Katamari Damacy, the premise of which is that the game player controls a small adhesive ball that rolls along, growing in size from the materials it accumulates as it rolls. The katamari begins by collecting rose petals, then grows in size until it can absorb entire planets. It eventually becomes the size of a star (that a prince uses to populate a cosmos his father destroyed).
} 
to taxpayers (Rich and Evans 2005), size is not often theorised as a crucial or even an ancillary aspect of citizenship. Framing larger size as an epidemic, threat and expense works to demarcate who is included in the national body politic.

For example, the 1974 report $A$ New Perspective on the Health of Canadians, recommended 'informing, influencing and assisting both individuals and organisations so that they will accept more responsibility and be more active in matters affecting mental and physical health' (Lalonde 1974: 66). This document signaled a shift in health care priorities, substantively addressing obesity as a problem that health promotion campaigns could resolve (Ellison, McPhail and Mitchinson 2016). Many of the causes cited for obesity rates - over-eating, high-fat intake, high carbohydrate intake, fad diets, lack of exercise, malnutrition, lack of recreation and lack of relief from work pressures - implicated citizens in projects of self-betterment.

The tone has not much changed since, with current public health 'approaches to combat obesity' (CPHI 2011: para. 3) consisting of health interventions at the individual level, community-level interventions designed to influence behaviour and public policy targeting social determinants of health. ${ }^{4}$ If anything, personal responsibilisation to enact a healthy

\footnotetext{
4 The Report is internationally renowned for its claim that a state health care system should invest in measures beyond caring for the sick. Declared at its outset: 'Good health is the bedrock on which social progress is built. A nation of healthy people can do those things that make life worthwhile, and as the level of health increases so does the potential for happiness' (Lalonde 1974: 5).
} 
subjectivity has intensified with increasing self-monitoring and tracking in the digital age.

For example, the 2016 Senate Report Obesity in Canada: A Wholeof-Society Approach for a Healthier Canada, compiled findings from sessions with experts whose testimony addressed 'diet, physical activity and best practices' (Ogilvie and Eggleton 2016: 1). The Report opens with the dire warning that Canadians are 'paying' with both 'their wallets' and 'their lives' for 'an obesity crisis' (iv). Such a warning situates the fat citizen both as a threat to public health standards and a drain on health care services. The Report quotes testimony from medical expert Laurie Twells, who claims that health care costs and lost productivity could amount to \$4.6-7.1 billion in annual loss, even as other sources suggest that fears of obesity overwhelming government health care coffers are proving to be unfounded (Ellison, McPhail and Mitchinson 2016). In quantifiable terms, the fat citizen is a failing citizen, their costs outweighing their contributions. But there's hope, if Canadians 'renew their efforts to eat healthy and get active - and government and industry ... give citizens the means and motivation to make informed lifestyle choices' (Ogilvie and Eggleton 2016: iv). $\underline{5}$

The construction of a national body politic highlighted by these reports impacts queer subjects and leads us to explore how our research

\footnotetext{
${ }^{5}$ In fairness, this latter Report highlights the virtual impossibility that rising obesity rates can be solely attributable to individual failing, and recommends a 'whole-of-society approach' over the framing of weight gain as personal responsibility. But this conclusion leads to the building of a large-scale apparatus for monitoring and managing weight in the population - surely a biopolitical project if there ever was one. Further, the strategies suggested remain largely biomedical and behaviouralist in nature.
} 
participants - queer persons with variant and shifting bodies, sizes and identities - perceive and practice their embodied subjectivities and enact sexual citizenship.

\section{Queering Weight: Confronting Compulsory Thinness in Clinical}

\section{Encounters}

For Michel Foucault, the embodied self is the ultimate 'make-work' project, shaped and constrained - but also produced - by, through and within biopolitical relations. The body becomes a practiced thing (Foucault 1977), an artifact sculpted and weathered by prevailing forces that work upon it. These forces manifest in a 'thoroughly heterogeneous ensemble' (194), made up of administrative, medical, scientific, educational and political institutions. All are vested with powers to administer and manage the lives of a citizenry. The deployment of power across this network directly impacts a citizen's body through 'technologies of the self' (Foucault 1988), or a 'repertoire of resources and biopedagogies with which citizens can work upon themselves' (Ward 2016: 225). The citizen is solidified by enacting control over their own body in accordance with instruction and expectation.

Biocitizens are at once expected to submit to medical expertise and to proactively manage possible future health risks (Novas and Rose 2000). People actively negotiate this terrain by, for example, resisting or taking up medical labels, ascribing power to or dismissing labels that have been applied to them, and so on (Rose 2007). Those 'expected to embrace and incorporate such strategies' into their lives are at times 'delightfully disrespectful, partially resisting calls to self-governance' (McPhail 2013: 
$290,300)$. Of course, people are not equally able to actively negotiate their medicalised and biopedagogised selves. As Rose reflects: 'some people are more medically made up than others - women more than men, the wealthy differently from the poor, children more than adults, and, of course, differently in different countries and regions of the world' (2007: 700). The 'delightfully disrespectful' subject may be taking significant social risks to engage in subversion (Novas and Rose 2000).

Bodies in negotiation with discourses of body management resonate with queer notions of compulsory heterosexuality. Coined by Adrienne Rich (1980), compulsory heterosexuality refers to the way political institutions structure and naturalise social and sexual relations as well as personal consciousness and desire. In other words, we come to sexual citizenship through the technologies of self that are available to us - technologies that operate predominantly along heteronormative lines. Resistance to compulsory heterosexuality takes queer forms, which Eve Kosofsky Sedgwick articulates as 'the open mesh of possibilities, gaps, overlaps, dissonance and resonances, lapses and excesses of meaning when the constituent elements of anyone's gender, of anyone's sexuality aren't made (or can't be made) to signify monolithically' (1993: 8). A queered self is a self whose identity is unsettled because the very foundations of identity and the apparatuses responsible for its production are made to shift beneath our feet.

Queer theory, with all its anti-identitarian motivations, unsettles other identity markers such as fatness. As Kathleen LeBesco attests: 'by queering corpulent bodies/politics, perhaps we can equally resist dominant discursive constructions of fatness, while opening new and playful sites for 
reconstructing fat bodies' (2006: 14). This 'potential queerness - and queer potential - of fat' (Wykes 2014: 3; Cooper 2016) upsets how fat bodies are structured as failures through compulsory thinness.

In our study, we find this dual construction of thinness as compulsory and fatness as failure:

And [my doctor] pushed back her, um, clipboard and started launching into this speech about how I shouldn't be eating burgers and fries and fettuccine alfredo, and I said, 'I don't', and she said, 'You must, look at you' (Vaska).

I got on the scale, even though I didn't really want to ... And I got off and [the nurse] was like, 'Look at this number'. And I looked and I just - It was so much heavier than I was expecting it to be ... and she was like, 'Well ... what are you going to do about it?' (Leigh).

Resonant in these encounters is the offloading of responsibility for managing medical conditions onto fat persons. Medical practitioners structure and shape a biopolitical relation with their patients, for they hold cognitive and social authority to make sense of their patients' somatic conditions (Wendell 1996). Implicit in medical diagnosis, then, is constructivist, power-inflected work, that is not ideologically neutral or a purely positivistic description (Cadwallader 2009). Medical practitioners echo and inform anti-obesity policy that is itself motivated by an investment in the bodies of a citizenry and the extent to which bodies are in excess. In this way, medical practitioners are prescribing and inscribing technologies of self, and are playing a role in the production of a particular biocitizenry. 
Despite its basis in limited and narrowly interpreted scientific evidence, the medicalisation and responsibilisation of fat is a politically captivating narrative (Rail, Holmes and Murray 2010; Wright 2009). When applied to fatness, the language of epidemic - typically reserved for infectious disease - is coloured with moral panic over health endangerment and economic crisis. Indeed, the framing of fatness as crisis produces 'fat bodies and fat subjects as both "diseased" on an individual level, and as parasitic on a social level, monopolizing healthcare resources while failing - or refusing - their responsibility as good neoliberal citizens to enact "proper" self-management through weight loss' (Wykes 2014: 2). One of our interview participants, Harper, felt this expectation to self-manage, along with the assumption that she had not been self-managing all along:

Every single time a health care professional sees me, there's assumptions about my body. There's assumptions that I don't work out, there's assumptions that all I do is eat. There's assumptions that all I do is overeating when I'm under eating. Um, and all these negative stereotypes that get attached to my body, and I'm like, whoa, you're so far off! You're so far off about your perceptions about my body!

Bodies so positioned on the battlefield, imagined to be riddled with plague and strapped down by ticking time-bombs made up of adipose tissue are subjected to varied techniques of governance in order to bring them in line with the appropriate citizen aesthetic. In this way, an uncritical embracing of the Canadian obesity epidemic has 'provided many new opportunities for the monitoring, regulating, and stigmatizing of 
“threatening" fat bodies' (McNaughton and Smith 2016: 125), all the while linking public health demands to personal responsibility.

\section{Making Queerness Weighty: Feeling the Viscosity of}

\section{Embodiment}

To make sense of how interview participants' reflections open up new possibilities for understanding queer(ly) fat bodies, we turn to the Deleuzian extension of Foucault's notion of decentralised power in the dispositif: an ensemble of knowledge, laws, institutions, systems, procedures and the like. The dispositif consists of 'heterogeneous lines of forces capable of generating a "surplus-value" that enables the apparatus to produce and make possible a subjectivity' (Yue 2009: 66). Technologies of the self move as 'lines of escape' or lines of flight, as uncharted trajectories away from the previously known (Deleuze 1992: 161), Here, the self we appear to be is a momentary intensification along gathered lines (Deleuze and Guattari 1987). The self, in other words, is an assemblage, or an event defined by and inseparable from its affective connections, which themselves are unstable. Deleuze favours creativity and changeability as valuable and necessary aspects of subjectivity (1992). This is highlighted by the way the body affectively transforms its practices and practiced self in assemblage with others.

For Sara Ahmed, this affective transformation involves 'stickiness'. A thing becomes sticky when we transfer affect, creating a 'withness' (2004: 130) or a binding agent along and across relationships. Through affective expression we adhere to and pick up debris along the way like katamari: sticking with friends, getting stuck in a problem, sticking to our convictions, 
sticking out a tumultuous romance. Ahmed plays upon the Deleuzian lines of flight that in definitive moments crystallise around what momentarily makes us, us, at least until we get unstuck and the katamari rolls along to new landscapes. We might similarly employ a concept like viscosity, a term used to describe uneven lava flows: 'the world is an immense mass of viscosities, becoming thicker here, and thinner there' (Saldanha 2006: 18). Instead of conceiving of the relationships between bodies, subjectivities and environments as solid, fixed and measurable, we must necessarily consider them as continually flowing and resisting, only momentarily fixed as they become.

We might come to understand fatness as a process of becoming in these moments where meaning thickens, or where bodies materialising as objects find meanings sticking to them. Fat bodies experience affective attachments when associated with laziness or overindulgence, lack of selfcontrol or self-discipline. They may be taken up as undesirable or fetishised sexual objects. They may become the stuff of dire medical prognosis. They may be coded as failures: causing concern, costing money, threatening a communal moral fiber, flirting with disease and death (see White 2012). They may acquire radically different meanings depending on their colour, density, ability, gender and sex (Rice 2014). But a closer reading is in order, for the instability of fatness - its very tendency to spill over and burst from imposed borderlines - may operate as a clear indication of the transformative potential of bodies to exceed their coding.

The viscosity of embodiment - where lines demarcating the delimiting body are never fully fixed - emerged as one of the key themes with research participants. Thus, participants' relationships to their bodies 
reflected sensitivity to changeability and would themselves affectively shift contingent on bodily becomings:

[My relationship with my body is] Sometimes, tumultuous and really cruel. Sometimes very loving. But very fluid and flexible (Ollie).

My relationship with my body is a complicated relationship that is ever changing and ever growing (Harper).

These relationships reflect a hopeful orientation toward body that conflicts with and subverts more rigid structurings of biocitizenship. Their openness to a multivalent and complex self, a self that moves and changes and produces varying affects, echoes Jack Halberstam's embrace of failure. For him, 'failing is something queers do and have always done exceptionally well' (2011: 3), to the extent that the failure and refusal to cohere with dominant and disciplined narratives makes possible subaltern avenues of expression and new potential futures.

Only the complexity of participants' bodily affects can be more viscous than fluid, and while there is promise in the opportunity to 'poke holes in the toxic positivity of contemporary thinking' (Halberstam 2011: 3), it is also possible for those common scripts about body to stick to the body for a time. Charlotte Cooper (2016) shares such a concern in her critical assessment of fat activisms, positing that the mantle of body positivity has oft been taken up within these movements in ways that overlook affective experiences of struggle. Emery's reflections illustrate the extent to which body positivity in our activisms can be welcoming while also producing split subjectivities or dissonant shifting affects: 
For a long time, there's been a conflict between the self that knows I should feel good about my body, and the self that is like, I wish I could be a little bit skinnier. It would be nicer and easier and I wouldn't have to feel so, like, worried about wearing shorts, or whatever it is. Or the stretch marks all over my hips'. Um, and so that multi-level dialogue, it still happens sometimes. It still sneaks in, despite all of the politics. Despite the like, rad fat people in my life.

For Emery, our politics play out within and against techne's that work to demarcate bodies as un/acceptable and un/worthy of belonging.

\section{Taking on the Homonation: Challenging Exclusion in Queer}

\section{Communities}

For Puar, homonationalism 'operates as a regulatory script not only of normative gayness, queerness, or homosexuality, but also of the racial and national norms that reinforce these sexual subjects' (2007: 2). Taken through our Deleuzian lens, queer citizenship operates as a 'constant process of becoming' (Awwad 2015: 24), differentiating the 'good queers' from the deviant ones. Queerness is implicated in the construction of respectable citizenship and the imperialist, white supremacist and classist biopolitics implicit in nation-building.

In the Canadian context, OmiSoore H. Dryden and Suzanne Lenon mobilise homonationalism to apprehend "how the "turn to life" for some lesbian-gay-queer subjects' is contingent on their qualifications for belonging and the uninterrupted processes of exclusion (2016: 6). Homonational citizens are in effect brought into the Canadian national mythos, which is already saturated with exclusionary practices: colonial 
violence, restricted immigration, criminalisation of the poor, elimination of the non-normative (the disabled, psychiatrically labelled), continued policing of queer culture. To be brought into the national mythos is to be aligned with a fixed and troubling line - a (former) line of flight that has been reterritorialised and, thus, re-inscribes the codings that the act of queering is meant to dismantle.

For Samantha Murray, processes of pathologisation and cultural anxieties around disruptions to normative aesthetics position the fat body as 'always already a queer body, or at least ... . a body that queers' (2009: 153). The fat-as-queer citizen is not one committed to a 'turn toward life' as long as fatness-as-obesity is understood to be a death sentence. Resources and instruction are available to direct the failing fat body toward thinness - or at least health - and this direction is encoded as for the public good. The activities organised to achieve these goals are practices of biocitizenship, 'mobilized around many projects of the self, all of which are designed to control the flesh' (Norman, Rail and Jette 2016: 358). Practices of diet and exercise are technés of proper citizenship.

Technés of proper citizenship extend to other boundary practices of inclusion/exclusion. Our interview data highlights how disabled queers are marginalised within queer community spaces. For example,one study participant, Raine, indicated: 'how can I be queer and Black? So many places that you go into, to this day, are so white, in the queer community'. Disabled queers also occupy the margins of queer community spaces when access issues and desirability politics impact their ability to participate. As disabled-identified Min makes clear in reference to troubles 
with accessibility, 'I've had experiences in places that are like, queer centered ... that have actually been negative'.

It is worth considering how fatness as a body marker maps onto race under the analytic lens of homonationalism. We have already established through existing literature that fatness has been taken up as itself a kind of queerness, a thing that is queer, given the quality of its abjectness (Murray 2009). Queer and fat politics are ostensibly interwoven. Perhaps in part due to fat politics being ardently queer, fat activisms too have been found to be all too white. Moreover, obesity is often articulated in public health literature as a sort of 'First World Problem': a problem of excess and luxury, infecting the core of industrialised civilizations rather than standing outside their borders as unacknowledged outsiders. If expressed as a 'Third World' issue in policy, for example in World Health Organization rhetoric, obesity is often seen as a problem associated with so-called 'westernisation' and the globalisation of western food and foodways (McPhail 2016). At the same time, fatness itself surfaces in westernised contexts as a stain against whiteness, as that which marks the unmarked normative (white nondisabled middle class) subject.

Perhaps it is for this reason that, even when playing out differently, there remains compelling explanatory force to notions of fat bodies as the wrong kind of queer, and as failed citizens with state apparatuses working against them. But there may be transformative potential in framing fatness as failure, in seeing how fatness moves through the margins of queer community arrangements. Cooper recognises the potential of out-queering queerness, or re-invigorating queer theory and practice with the introduction of fat. Such a move serves as reminder that the queer posture 
is meant to 'relinquish the desire to be normal' (2016: 193) and to revel in this recalcitrance. Ollie offers one such example of the rewards gained from failing as a fat queer subject in-community:

The queer kink community . . . it's wonderful. Because it's so accepting. And like, I really specify the queer kink community, because the kink community is really heteronormative, power play, really binary; and the [larger] queer community is not as accepting as people would like to imagine it is. So kind of the onslaught of the two - you have these wonderful, dynamic, accepting, welcoming people and it's lovely.

\section{Un/Becoming Sexual Citizens: Finding Subversive Potential in}

\section{Active Constructions of Self}

We need not be trapped within biocitizenship discourses - while we might never be disentangled entirely, we are never solely determined by these discourses. People are always within a matrix of networks that contribute to subjectification (Novas and Rose 2000); and yet, within this space, there is room for active construction, even from the margins.

Dispositives undoubtedly uphold the divide between appropriately and perversely queer subjects and determine who will be 'invited into life' (Puar 2007: 165). However, dispositives also give energy to heterogenous lines of force that form assemblages of race, ability, class and other configurations (Puar 2012) that distinguish between those queer subjects imagined as qualifying for, and those disqualified from, citizenship. Here, intersectional identities re-envisioned as events or actions 'are the byproducts of attempts to still and quell the perpetual motion of 
assemblages, to capture and reduce them, to harness their threatening mobility' (Puar 2007: 213). But such operations have not quelled the development of mobile, intersectional queer fat communities and practices. Queerness - and by extension fatness, insofar as we find queer potential in fatness - continues to come 'forth at us from all directions, screaming its defiance [recognising] other contingencies of belonging (melding, fusing, viscosity, bouncing)' (211).

We see this defiance when fat subjects recalibrate and redeploy the technologies of self to push back against the dispositives that invest power in bodies. Our research participants spoke at length and across interviews about the joys of eating practices, for example, from lesbian potlucks to discovering cooking as a hobby. "l eventually started reclaiming my own relationship with food', says Harper, as though eating as a practice - surely a personal and intimate activity, one deeply tangled in the flows into, through and out of the body - was once not quite hers.

Bodily presentation also operates as the condition producing and enabling a practiced body, even as the practices themselves may be reoriented through bodily demand and desire. Gender expression plays a key role in corporeal presentations and how size and shape is taken up, where for instance, Emery claims femme-ness for the sake of empowerment and self-care, while Taylor feels most comfortable enacting butch-ness. Clothing and hair become political statements, marks of defiance:

I don't know how desirable the world thinks I am, but when I dress a certain way - I feel like l'm desirable all of the time, and I like to dress for me to feel good about myself, so l'm always - you may 
look at me and think, 'Is that what she's wearing today?' but I put a lot of thought into everything (Vaska).

Disability and race also play a critical role in bodily self-styling.

Participants moving through and adhering to multiple marginalised identities creatively re-signified their visible markers of embodied difference as a way of disrupting exclusions within queer culture:

I dress a certain way. So this cane here is my everyday cane. I have another cane that I use for going out. And this is my going out walker, and I have another walker that is more mundane. So there are little things that I try to do. [OK. What makes the distinction between the everyday and the going out? How it looks and the style?] Yes, the style. So my - I didn't bring it today because today was just - but it's lavender. And whenever I use it, I always get comments about it (Sanaa).

Our participants shared with us the varied activities central to their un/making, the role their own desires played in directing their lines of flight: they invest in non-normativities and find vitality and value in those investments. In so doing, they point the way to new sorts of citizenship. They challenge and disrupt their borderlines in their presented becomings, their comings-out, their celebration of and delight in failed forms of citizenship.

\section{Conclusion}

Participants' stories speak to the complex, viscous potentialities of bodies that challenge their biopolitical constraints. While queer communities might be configured as spaces of opening to difference - and 
offer the possibility of queering fatness in a society bent upon personal responsibilisation for transgressive bodies - we cannot ignore the ways homonationalism dictates which expressions of queerness materialise. Our participants articulated complex belongings and non-belongings to such communities, resisting and negotiating transgressing and adopting; dictating and following. Like katamari, participants assembled sticky affective ties throughout their lives as they flowed into and out of communities and enacted citizenship in and beyond queer communities.

Participants' narratives offer us the opportunity to contribute to assemblages that open to - rather than foreclose, call out and make abject - difference. Perhaps most importantly, participants' accounts offer us an opportunity to avoid naming some spaces as always safe for those bodies called to account for managing individually conceptualised 'risks'. Paradoxically, by referring to a space as 'safe,' homonationalist practices may territorialise space; embodied subjects who feel ill at ease in these spaces are then further marginalised. These stories encourage us to consider all spaces as continual (re)negotiations.

What possibilities exist for those whose bodies transgress, on multiple levels, the rigid strictures for proper biocitizenship? How might we invite openness to difference without congealing new dictates for bodies and responsibilising individual people to be the bearers of new lines of flight? Questions about un/becoming queer fat bodies in, through and beyond communities and affective relations drive a desire to understand participants' narratives as deeply tied to a project of becoming unfixed, shifting, untethered. The project of creating an assemblage open to difference is necessarily one that implicates embodied becomings, affective 
relationships and systemic shifts. The project cannot be one enacted by individuals acting in accordance with social dictates or it risks simply reproducing the structures that territorialise, anew.

\section{References}

Ahmed, Sara (2004), 'Affective Economies', Social Text, 22:2, pp. 117139.

Awwad, Julian (2015), 'Queer Regulation and the Homonational Rhetoric of Canadian Exceptionalism', in OmiSoore H. Dryden and Suzanne Lenon (eds.), Disrupting Queer Inclusion: Canadian Homonationalisms and the Politics of Belonging, Vancouver:UBC Press, pp. 19-34.

Canadian Population Health Initiative (CPHI) (2011), Obesity in Canada: A Joint Report from the Public Health Agency of Canada and the Canadian Institute for Health Information, Ottawa: Public Health Agency of Canada \& Canadian Institute for Health Information.

Cadwallader, Jessica (2009), 'Diseased States: The Role of Pathology in the $(\mathrm{Re})$ Production of the Body Politic', in Nikki Sullivan and Samantha Murray (eds.), Somatechnics: Queering the Technologisation of Bodies, Burlington: Ashgate, pp. 13-28.

Cooper, Charlotte (2016), Fat Activism: A Radical Social Movement, Bristol: Hammeron Press.

Deleuze, Gilles (1992), 'What Is a Dispositive?', in Timothy J. Armstrong (ed.), Michel Foucault: Philosopher, Hemel Hempstead: Harvester Wheatsheaf, pp. 159-168. 
Deleuze, Gilles and Felix Guattari (1987), A Thousand Plateaus: Capitalism and Schizophrenia, trans. Brian Massumi, Minneapolis: University of Minnesota Press.

Dryden, OmiSoore H. and Suzanne Lenon (2016), 'Interventions, Iterations, and the Interrogations that Disturb the (Homo)National', inOmiSoore H. Dryden and Suzanne Lenon (eds.), Disrupting Queer Inclusion: Canadian Homonationalisms and the Politics of Belonging, Vancouver: UBC Press, pp. 3-18.

Ellison, Jenny, Deborah McPhail and Wendy Mitchinson (2016), 'Introduction: Obesity in Canada', in Jenny Ellison, Deborah McPhail and Wendy Mitchinson (eds.), Obesity in Canada: Critical Perspectives, Toronto: University of Toronto Press, pp. 3-30.

Foucault, Michel (1977), 'Confession of the Flesh', in Colin Gordon (ed.), Power/Knowledge: Selected Interviews \& Other Writings, New York: Pantheon Books, pp. 194-228.

Foucault, Michel (1988), Technologies of the Self: A Seminar with Michel Foucault, Luther H. Martin, Huck Gutman and Patrick K. (eds.) Hutton, Boston: University of Massachusetts Press.

Giddens, Anthony (1984), The Constitution of Society, Berkeley: University of California Press.

Halberstam, Judith (2011), The Queer Art of Failure, Durham: Duke University Press.

Lalonde, Marc (1974), A New Perspective on the Health of Canadians: A Working Document, Ottawa: Ministry of National Health and Welfare. 
LeBesco, Kathleen (2006), Revolting Bodies: The Struggle to Redefine Fat Identity, Amherst: University of Massachusetts Press.

McNaughton, Darlene and Cynthia Smith (2016), 'Diabesity, or the "Twin Epidemics": Reflections on the latrogenic Consequences of Stigmatizing Lifestyle to Reduce the Incidence of Diabetes Mellitus in Canada', in Jenny Ellison, Deborah McPhail and Wendy Mitchinson (eds.), Obesity in Canada: Critical Perspectives, Toronto: University of Toronto Press, pp. 122-147.

McPhail, Deborah (2013), 'Resisting Biopedagogies of Obesity in a Problem Population: Understandings of Healthy Eating and Healthy Weight in a Newfoundland and Labrador Community', in Lee Monaghan, Rachel Colls and Bethan Evans (eds.), Obesity Discourse and Fat Politics: Research, Critique and Interventions, New York: Routledge, pp. 289-303.

McPhail, Deborah (2016), 'Having Your Jigs Dinner and Eating It, Too: Newfoundland Obesity and the Affects of Tradition', in Jenny Ellison, Deborah McPhail and Wendy Mitchinson (eds.), Obesity in Canada: Critical Perspectives, Toronto: University of Toronto Press, pp. 320341.

Murray, Samantha (2009), 'Banded Bodies: The Somatechnics of Gastric Banding', in Nikki Sullivan and Samantha Murray (eds.), Somatechnics: Queering the Technologisation of Bodies, Burlington: Ashgate, pp. 153-170.

Nigianni, Chrysanthi and Merl Storr (2009), Deleuze and Queer Theory, Edinburgh: Edinburgh University Press. 
Norman, Moss E., Genevieve Rail and Shannon Jette (2016), 'Screening the Un-Scene: Deconstructing the (Bio)Political of Storytelling in a Canadian Reality Makeover Weight Loss Series', in Jenny Ellison, Deborah McPhail and Wendy Mitchinson (eds.), Obesity in Canada: Critical Perspectives, Toronto: University of Toronto Press, pp. 342372.

Novas, Carlos and Rose, Nikolas (2000), 'Genetic Risk and the Birth of the Somatic Individual', Economy \& Society, 29:4, pp. 485-513.

Ogilvie, Kelvin K. and Art Eggleton (2016), Obesity in Canada: A Whole-ofSociety Approach for a Healthier Canada, Ottawa: Report of the Standing Senate Committee on Social Affairs, Science and Technology.

Puar, Jasbir K. (2007), Terrorist Assemblages: Homonationalism in Queer Times, Durham: Duke University Press.

Puar, Jasbir K. (2012), "I Would Rather Be a Cyborg Than a Goddess": Becoming-Intersectional In Assemblage Theory', philoSOPHIA, 2:6, pp. 49-66.

Rail, Geneviève, David Holmes and Stuart J. Murray (2010), 'The Politics of Evidence on "Domestic Terrorists": Obesity Discourses and Their Effects', Social Theory \& Health, 8:3, pp. 259-279.

Rice, Carla (2014), Becoming Women: The Embodied Self in Image Culture, Toronto: UT Press.

Rich, Adrienne (1980), 'Compulsory Heterosexuality and Lesbian Existence', Signs, 5:4, pp. 631-660. 
Rich, Emma and John Evans (2005), 'Fat Ethics: The Obesity Discourse and Body Politics', Social Theory \& Health, 3:4, pp. 341-358.

Rose, Nikolas (2007), 'Beyond Medicalization', Lancet, 369, pp. 700-701.

Saldanha, Arun (2006), 'Reontologising Race: The Machinic Geography of Phenotype', Environment and Planning D: Society and Space, 24:1, pp. 9-24.

Sedgwick, Eve Kosofsky (1993), Tendencies, Durham: Duke University Press.

Ward, Pamela (2016), 'Obesity, Risk, and Responsibility: The Discursive Production of the "Ultimate At-Risk Child"', in Jenny Ellison, Deborah McPhail and Wendy Mitchinson (eds.), Obesity in Canada: Critical Perspectives, Toronto: University of Toronto Press, pp. 218-244.

Wendell, Susan (1996), The Rejected Body, New York: Routledge.

White, Francis Ray (2012), 'Fat, Queer, Dead: "Obesity” and the Death Drive', Somatechnics, 2:1, pp. 1-17.

Wright, Jan (2009), 'Biopower, Biopedagogies and the Obesity Epidemic', in Jan Wright and Valerie Harwood (eds.), Biopolitics and the 'Obesity Epidemic', New York: Routledge, pp. 1-14.

Wykes, Jackie (2014), 'Introduction: Why Queering Fat Embodiment?', in Cat Pause', Jackie Wykes and Samantha Murray (eds.), Queering Fat Embodiment, Burlington: Ashgate, pp. 1-12.

Yue, Audrey (2009), 'Asian Sex Workers in Australia: Somatechnologies of Trafficking and Queer Mobilities', in Nikki Sullivan and Samantha 
Murray (eds.), Somatechnics: Queering the Technologisation of Bodies, Burlington: Ashgate, pp. 65-86. 